and Hygiene

Elsevier Editorial System(tm) for Transactions of the Royal Society of Tropical Medicine Manuscript Draft

Manuscript Number: TRSTMH-D-09-00346R1

Title: The dangers of an adventurous partner: Cordylobia anthropophaga infestation in London

Article Type: Case Report

Keywords: Cutaneous myiasis; Cordylobia anthropophaga; returning travellers

Corresponding Author: Dr James Whitehorn,

Corresponding Author's Institution: Hospital for Tropical Diseases

First Author: James Whitehorn

Order of Authors: James Whitehorn; Cheryl Whitehorn; Navin A Thakrar; Martin J Hall; Peter GodfreyFaussett; Robin Bailey

Abstract: We describe a case of cutaneous myiasis caused by Cordylobia anthropophaga acquired in the UK from contact with another person's clothes. We propose that this diagnosis should be considered in both returning travellers and also their household contacts. 


\section{Revision notes for manuscript TRSTMH-D-09-00346}

1. The statement defining cutaneous myiasis has been adjusted to the "infestation of vertebrates" in order to broaden the definition as suggested.

2. The term "infection" has been replaced by "infestation" throughout the manuscript.

3. The statement regarding extraction of Cordylobia has been adjusted to mention more complicated infestations and thus more complicated extractions (e.g. body orifices and mucous membranes).

4. The typing error in reference 5 has been corrected.

5. A statement of scale has been added to the figure legend.

6. Author's names have been adjusted to the suggested format.

7. City and country have been included to all affiliations

James Whitehorn 


\title{
The dangers of an adventurous partner: Cordylobia anthropophaga infection-infestation in London
}

\author{
J.S. Whitehorn ${ }^{1,2^{*}}$, C. Whitehorn ${ }^{2}$, N.A. Thakrar ${ }^{3}$, M.J.R. Hall ${ }^{4}$, P. Godfrey- \\ Faussett $^{1,2}$, R. Bailey ${ }^{1,2}$
}

1. Hospital for Tropical Diseases, University College London Hospitals NHS Trust, UK

2. London School of Hygiene and Tropical Medicine, UK

3. Holly Road Medical Centre, London, UK

4. Natural History Museum, London, UK

* Corresponding author. Present address: Hospital for Tropical Diseases, Mortimer Market Centre,

Capper Street, London WC1E 6JB, UK. Tel.: +44 8451555000.

E-mail address: james.whitehorn@uclh.nhs.uk (J. Whitehorn).

\section{Summary}

We describe a case of cutaneous myiasis caused by Cordylobia anthropophaga acquired in the UK from contact with another person's clothes. We propose that this diagnosis should be considered in both returning travellers and also their household contacts.

\section{Key words}

Cutaneous myiasis; Cordylobia anthropophaga; returning travellers 


\section{Introduction}

Cutaneous myiasis is occasionally seen in travellers from endemic areas. ${ }^{1}$ We report a case of cutaneous myiasis acquired in the UK after contact with clothes of a returning traveller. We propose that this diagnosis should be considered in both travellers with skin lesions but also their household contacts.

\section{Case report}

A previously healthy 40 -year-old man presented to our tropical medicine clinic on the $29^{\text {th }}$ April 2009 after extracting a maggot from his forearm. In the week prior to presentation he had developed an itchy swelling with associated erythema on his right forearm. He attended his local emergency department where it was thought that he had scratches from gardening that had become infected. He was prescribed flucloxacillin which did not help his symptoms. The following day he saw his general practitioner (GP) and was given a tetanus booster and was advised to place the forearm in hot water to help the swelling. After taking his GP's advice he was alarmed to see a maggot protruding from his forearm. Remaining calm he used a pair of tweezers to extract the intact maggot, which he took to his doctor. His GP had seen similar cases when he lived in Africa and referred him to the Hospital for Tropical Diseases. The maggot was identified as a third instar larva of Cordylobia anthropophaga (Figure 1). On review of our patient's travel history he had been no further afield than Italy. However his partner had recently returned from a trip to rural Uganda. She had washed her clothes but had not ironed them.

\section{Discussion}

C. anthropophaga, the Tumbu fly, is endemic to sub-Saharan Africa. ${ }^{1}$ It is a cause of myiasis, the infestation of living vertebrates by the larvae of various insects. ${ }^{1}$ Typically the adult females lay eggs on dry sandy soil but they may lay their eggs on drying clothes. Larvae hatch from the eggs within 1-3 days and gain access to their human host when the clothes are next worn. The larvae invade the host and develop over about 7-10 days, causing formation of a furunculoid lesion. The dark head of the boil represents the posterior spiracles of the larva. Hot-ironing all clothes after drying can prevent infection. ${ }^{2}$ Treatment of infection-infestation involves partially suffocating the larva by covering the lesion with petroleum jelly. ${ }^{2}$ In response to this the larva emerges enough to allow it to be extracted with forceps. Care must be taken to avoid macerating the larva as this can result in an inflammatory reaction. Fortunately the shape of the Tumbu fly larva is such that extraction is usually relatively straightforward, except in cases where infestation with multiple larvae or infestation of a body orifice or mucous membrane has occured. In contrast extraction of the human bot fly larva (Dermatobia hominis) can require a more complicated procedure. ${ }^{2}$ 
C. anthropophaga infestationsctions are rarely acquired outside of Africa. The literature reports one case in Spain, two cases in Britain and one in

Portugal. ${ }^{3,4,5}$ It is possible that our patient was infected-infested as a result of contact with some of his partner's clothes from Uganda as the first instar larva can survive for up to 15 days after hatching. ${ }^{6}$ This case illustrates that cutaneous myiasis should be considered as a diagnosis not only in returning travellers with skin lesions but also their household contacts.

After extraction of the larva our patient made a good recovery, but he left the clinic planning to thoroughly wash and iron all his and his partner's clothes.

\section{References}

1. Hall M, Wall R. Myiasis of humans and domestic animals. Adv Parasitol 1995; 35: 257 - 334.

2. Jelinek T, Nothdurft HD, Rieder N, Löscher T. Cutaneous myiasis: review of 13 cases in travelers returning from tropical countries. Int $J$ Dermatol 1995; 34: 624 - 626.

3. Laurence BR, Herman FG. Tumbu fly (Cordylobia) infection outside Africa. Trans R Soc Trop Med Hyg 1973; 67: 888.

4. Baily GG, Moody AH. Cutaneous myiasis caused by larvae of Cordylobia anthropophaga acquired in Europe. Br Med J 1985; 290: $1473-74$.

5. Curtis SJ, Edwards C, Athulathmuda C, Paul J. Case of the month: Cutaneous myiasis in a returning traveller from the Algarve: first report of tumbu maggots, Cordylobia anthropophaga, acquired in Portugal. Emerg Med J 2006; 23: 236 - 7.

6. Blacklock B, Thompson MH. A study of the tumbu-fly Cordylobia anthropophaga Grünberg in Sierra Leone. Ann Trop Med Parasitol 1923; 17: 443 - 502.

\section{Figure legend}

Figure 1: Third instar larva of $C$. anthropophaga from our patient (Scale in $\underline{\mathrm{mm})}$

\section{Authors' contributions}

JSW, NAT, PGF and RB were involved with the clinical care of the patient; $\mathrm{CW}$ processed the sample and took the photograph; MJRH provided expert 
entomology advice; JSW, PGF and RB prepared the manuscript. All authors read and approved the final manuscript. JSW is the guarantor of the paper.

\section{Funding}

None

\section{Conflicts of interest}

None declared

\section{Ethical approval}

Not required. The patient gave informed consent for this case report to be written. The patient's assessment and treatment were in accordance with standard UK clinical practice. 


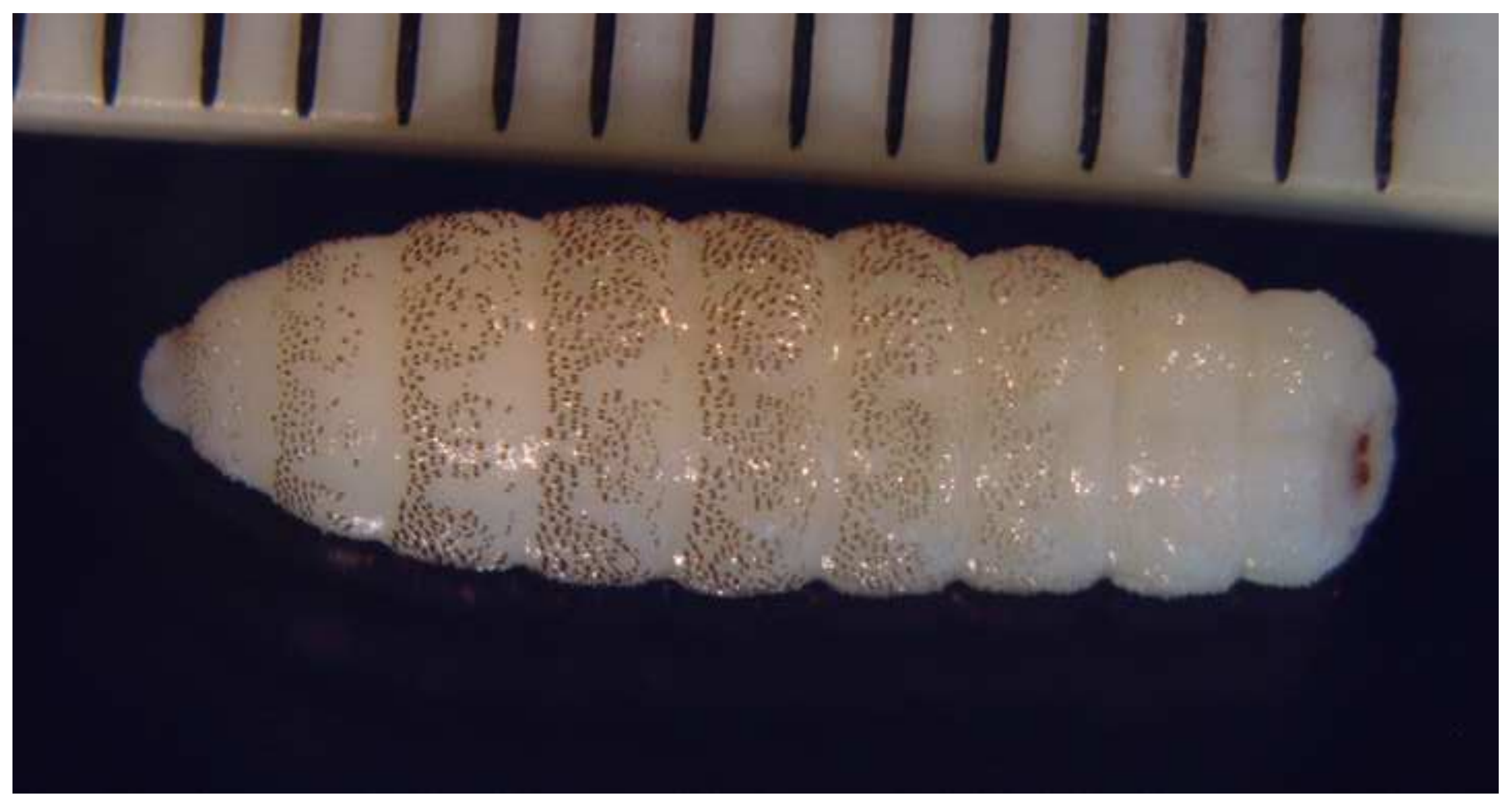

